\title{
Finite element simulation of laser cutting process of steel sheet
}

\author{
Jozef Meško ${ }^{1}$, Andrej Zrak ${ }^{1}$, Rastislav Nigrovič ${ }^{1, *}$, Milan Žmindák ${ }^{2}$ \\ ${ }^{1}$ UNIZA, Faculty of Mechanical Engineering, Department of Technological Engineering, Univerzitna \\ 8215/1, 01026 Žilina, Slovakia \\ ${ }^{2}$ UNIZA, Faculty of Mechanical Engineering, Department of Applied Mechanics, Univerzitna 8215/1, \\ 01026 Žilina, Slovakia
}

\begin{abstract}
Lasers are widely used in industry as cutting tools due to ultra flexibility of the cutting conditions, obtaining high quality end product, quick set up, nonmechanical contact between the workpiece and the tool, and small size of the heat affected zone. In the present study, laser gas assisted cutting process is examined. The laser cutting sheet solution is practically always very convenient compared to conventional technologies and brings the greatest cost savings in the manufacturing process.
\end{abstract}

Keywords: Laser cutting, FEM, Simulations of laser cutting, Finite element mesh

\section{Introduction}

Material cutting is still a very important manufacturing operation. A number of methods are used for this, each of which has created its area of optimal use. Each of them has some deficiency that prevents universal use. That is the reason, why there are still more and more modern procedures. The thermal cutting of the material can be included in the manufacturing process as a material preparation operation. Under this term, we mean cutting technology, working on the principles of local melting, combustion, evaporation, or possibly combining of these phenomena. In this technology, where energy is needed to initialize the process, and it is supplied by different heat sources. Laser cutting is applicable to a wide variety of construction materials: unalloyed and low alloy steel, high alloy steel and nickel alloys, non-ferrous metals and their alloys $(\mathrm{Al}, \mathrm{Cu})$, highly reactive materials and their oxygen-sensitive alloys (Mg, Ti), non-metallic materials (plastics, composites, wood, glass) $[1,2,7]$.

\footnotetext{
*Corresponding author: rastislav.nigrovic@fstroj.uniza.sk

Reviewers: Petr Horyl, Josef Soukup
} 


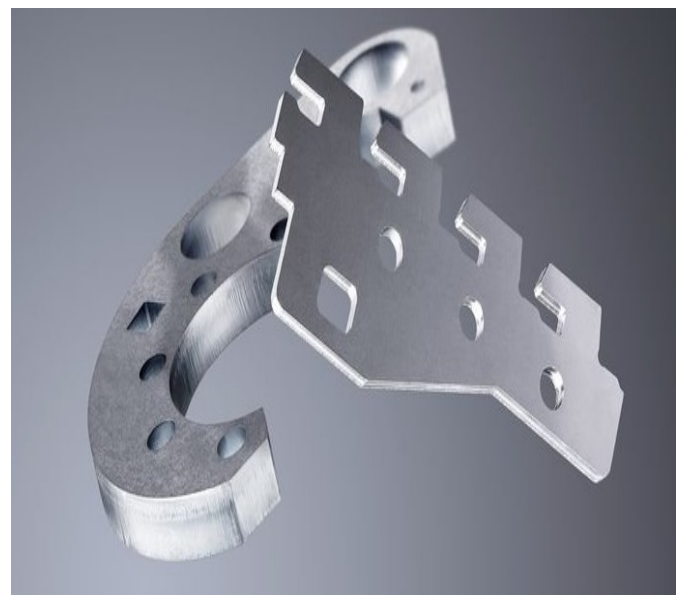

Fig. 1. A demonstration of a laser workpiece

When the laser beam impacts the material, there occurs an interaction between that material and the laser beam. The subsequent processes that take place during the material cutting and the effect on the material properties following the focused beam impact, mainly depend on the chemical composition of the material being cut and on the quality of its surface which was machined by milling in our case.

In thermal cutting of metallic materials by a laser, it is always necessary first to create a hole in the processed material, from which the cutting would continue. Making the hole is based on the laser drilling principle and has slightly different characteristics of the course than that of the actual cutting. The impacting laser beam transmits the kinetic energy of the material photons, which converts into heat that melts and partially evaporates the material being heated. The surroundings of the laser beam inflammation site (in the material being cut) contain gases that get ionized at the moment of the beam impacting the material and change to plasma. The material being cut sublimates into a gaseous state, and is blown from the material to the environment by the action of an assist gas under a relatively high pressure. Part of the material, which does not pass into a gaseous state, is blown in the liquid form by the flowing assist gas. The above-mentioned process causes formation of a pit in the material being cut, and the laser beam can penetrate continuously deeper, which results in depth melting of the material $[1,2,7]$.

\section{Theoretical foundations}

The heat transfer condition, which includes the material characteristics of the sample for simulation, is defined by Equation.

$$
\rho * c_{p} * \frac{6 T}{6 t}=\nabla *(k \nabla T)
$$

Where:

$\rho$ - density $\left[\mathrm{kg} / \mathrm{m}^{3}\right]$,

$\mathrm{cp}$ - the specific heat capacity at the const. pressure [J/kg.K],

$\mathrm{T}$ - temperature $\left[{ }^{\circ} \mathrm{C}\right]$,

$\nabla$ - nabla operator,

$\mathrm{k}$ - thermal conduction [W/m.K],

t- time [s]. 
An introductory step for creating a model of the laser cutting process is a compact analysis of the problem and the definition of the result, especially from that point of view, so that it is clear what is required from the simulation. The output that is the desired simulation result can accurately quantify the heat in the coordinate system $[x, y, z, t]$, where $\mathrm{x}, \mathrm{y}, \mathrm{z}$ are the coordinates defining the position of the point with respect to the axis $\mathrm{x}, \mathrm{y}$, Defines the exact time period in which the point temperature is quantified. An important step is to correctly define the total heat source, respectively. The heat input which is then dispersed in the surrounding material. Said method of defining a heat source is performed on the basis of a mathematical relationship in which the coefficient of reflectivity of the surface to which the laser beam enters, the coefficient of energy absorption of the photon flux through the material and the analytical function representing the 2D Gaussian curve are included as variables. The equation defines a point thermal source. The next step is to determine the correct networking of the model. The point heat source, which represents the power of the photons moving in the laser beam, is defined as the boundary condition in the entire domain in the simulated design. This resource is defined by Equation 2, which is specified in the Comsol Multiphysics 4.4 program as a variable, dependent on the global system $\mathrm{x}, \mathrm{y}, \mathrm{z}[3,5]$.

$$
\left.Q(x, y, z)=Q_{0} *\left(1-R_{c}\right) * \frac{A_{c}}{\pi * 6_{x} * 6_{y}} * e^{-\left[\frac{\left(x-x_{0}\right)^{2}+\left(y-y_{0}\right)^{2}}{z * 6_{x}^{2}} z^{2} * 6_{y}^{2}\right.}\right] * e^{-A_{c} * z}
$$

Where:

$\mathrm{Q}_{0} \quad$ - total heat supplied by the laser beam [J],

$\mathrm{R}_{\mathrm{c}} \quad$ - coefficient of reflectivity of the cut material,

$\mathrm{A}_{\mathrm{c}} \quad$ - absorption coefficient,

$\sigma_{\mathrm{x}} \quad$ - standard deviation of the laser in $\mathrm{x}$ direction [mm],

$\sigma_{\mathrm{y}} \quad$ - standard deviation of the laser in y direction [mm],

$\mathrm{x}_{0},\left(\mathrm{y}_{0}\right)$ - center of beam path in $\mathrm{x},(\mathrm{y})$ direction $[\mathrm{mm}]$.

\section{Model FEM}

\subsection{Simulation of steady-state lasers with constant power}

The simulation was generated as a process of heating the plate. The material properties of the board are considered to be constant - simulation does not involve a change in the material phase. The refractive index of the steel is defined by the reflection coefficient and the energy absorption coefficient by the material. The material model represents a plate whose sides except the top are considered to be heat insulated. The movement of the laser beam is characterized by $\mathrm{x}$ and $\mathrm{y}$ coordinates, and in the plane $\mathrm{xy}, \mathrm{z}=0$ is on the surface of the plate. Parameters $\mathrm{x} 0$ and $\mathrm{y} 0$ serve to enter the shift of the center of the laser beam. The diameter of the incident laser beam in practice has a changing value, the shifting of the laser beam focus point, and therefore the change of the incident beam diameter is defined by the standard deviation parameters $\sigma_{\mathrm{x}}$ and $\sigma_{\mathrm{y}}$.

At the beginning was created, a model of a laser, which is considered as a heat source, with a constant power that does not move on the surface of the plate. The method was designed to investigate the heat dissipation in the plate to which the laser beam enters in continuous mode for 3 seconds. The analytical feature representing the 2D Gaussian curve was then created. This function is given by a symbolic expression and has the ability to bind arguments in a repeated function solution. [4, 6] 
Table 1. Variables used for simulation

\begin{tabular}{|c|c|c|}
\hline Mark & Set value & Setting characteristics \\
\hline $\mathrm{x}_{0}$ & $0[\mathrm{~mm}]$ & Center of laser beam path \\
\hline $\mathrm{y}_{0}$ & $0[\mathrm{~mm}]$ & Center of laser beam path \\
\hline $\mathrm{Q}_{0}$ & $3200[\mathrm{~W}]$ & Total laser beam power \\
\hline $\mathrm{sig}_{\mathrm{x}}$ & $0,5[\mathrm{~mm}]$ & Standard deviation in $\mathrm{x}$ direction \\
\hline $\mathrm{sig}_{\mathrm{v}}$ & $0,75[\mathrm{~mm}]$ & Standard deviation in y direction \\
\hline $\mathrm{Ac}$ & $0,50[1 / \mathrm{cm}]$ & Absorption coefficient \\
\hline $\mathrm{Rc}$ & 0,50 & Reflection coefficient \\
\hline $\mathrm{L}$ & $100[\mathrm{~mm}]$ & Dimension of the square plate \\
\hline $\mathrm{Lz}$ & $10[\mathrm{~mm}]$ & Thickness of the board \\
\hline $\mathrm{t}$ & $3[\mathrm{~s}]$ & The time of the laser beam on the plate \\
\hline
\end{tabular}

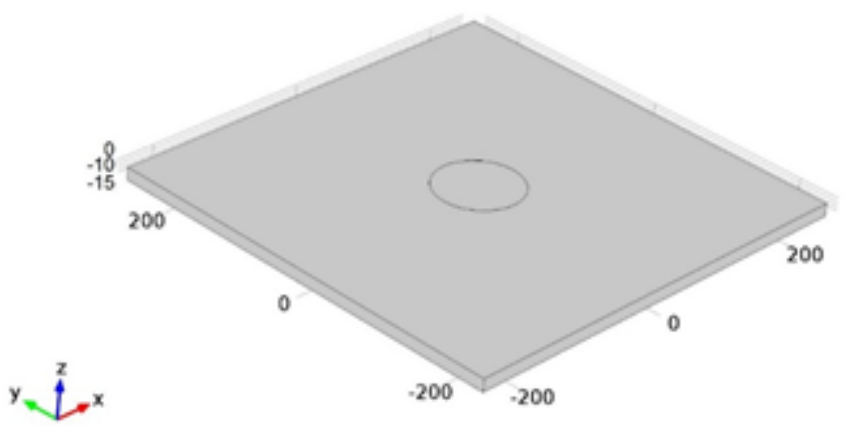

Fig. 2. Geometric model of the board

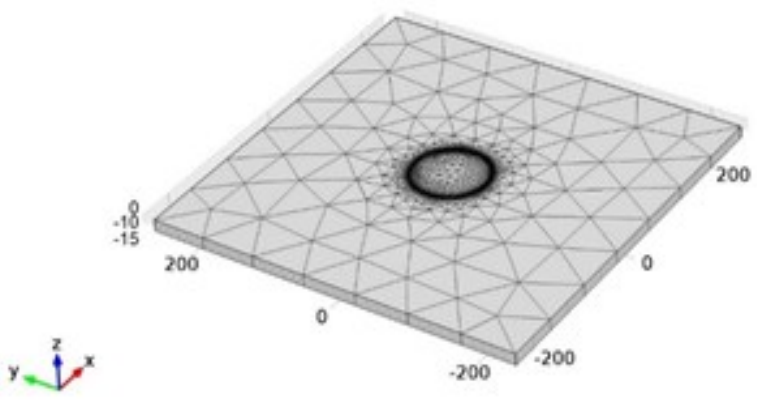

Fig. 3. Finite element mesh 


\section{Numerical results}

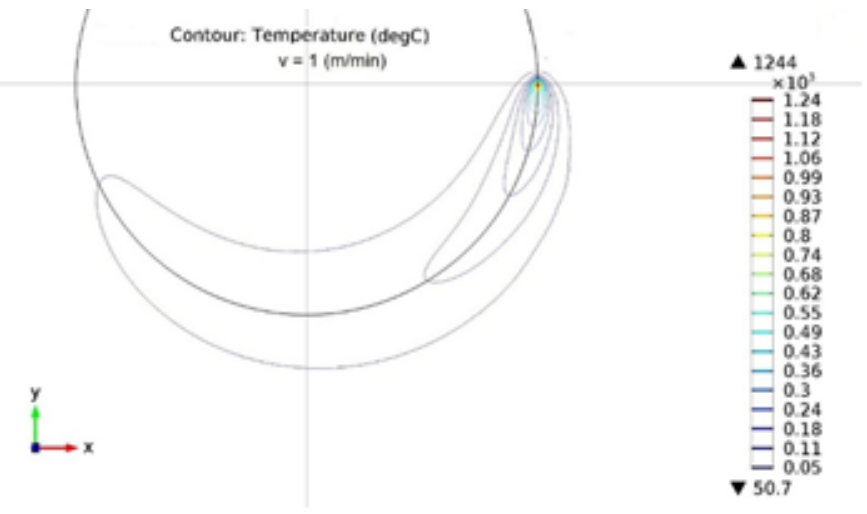

Fig. 4. Temperature fields at a cutting speed of $1 \mathrm{~m} / \mathrm{min}$

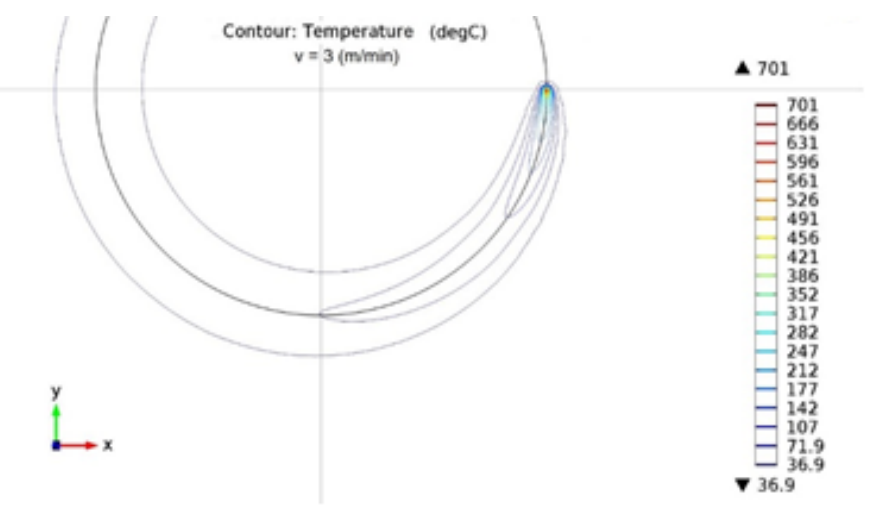

Fig. 5. Temperature fields at a cutting speed of $3 \mathrm{~m} / \mathrm{min}$

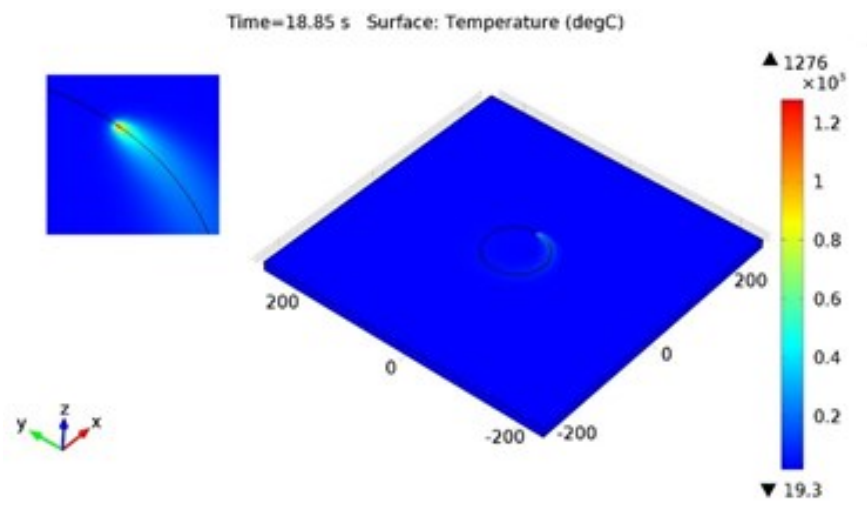

Fig. 6. Temperature field model 


\section{Conclusion}

Based on the model of heat transfer in the material during laser cutting, it is possible to understand the principle of heat conduction from the cutting point to the surrounding material. This mechanism is particularly important when dealing with the problem of cutting rough metal sheets, Small parts with a complicated cutting path so that a relatively large amount of heat is introduced into the material. After is the principle of heat dissipation in the cut material known, depending on the time, it is possible to design the ideal arrangement of parts and the processing of the components so that the cutting edge of the material causing the deformation is not bounded at the defined part of the component. Based on the analysis of simulated model results, it can be stated that the temperature of the material at the point of cutting immediately at the edge of the laser beam is assumed to be approximately $1700{ }^{\circ} \mathrm{C}$ and the maximum stress due to the thermal expansion of the material is assumed to be approximately $1300 \mathrm{MPa}$. The temperature of the material at the cutting location is relatively high, but with increasing distance from the cutting point it drops sharply, e.g. At a distance of $10 \mathrm{~mm}$ from the source of heating, the temperature of the material is $100^{\circ} \mathrm{C}$.

Research presented in this paper was partially financially supported through realization of projects KEGA 014ŽU-4/2016 - Responsible investigator: prof. Jozef Meško, MSc., Ph.D.

\section{References}

1. L. C. Caristan, Laser cutting guide for manufacturing. Dearborn, Michigan, USA: Society of Manufacturing Engineers, 452 p. ISBN 0-87263-686-0 (2004)

2. W. T. Silvfast, Laser Fundamentals. (Cambridge University Press, 666 p. ISBN 0-52183345-0, 2004)

3. J. Meško, A. Zrak, Analysis of heat transfer in laser cutting problems. Analysis of technology in various industries: monography, Chapter 6, Częstochowa: Oficyna Wydawnicza SMJiP, ISBN 978-83-63978-11-2 (2014)

4. P. Novák, J. Meško, M. Žmindák, Finite element implementation of multi-pass fillet weld with phase changes. Manufacturing technology, Journal for science, research and production 13 (1), 79-85 (2013)

5. M. Žmindák, Z. Pelagič, P. Pastorek, M. Moličan, M. Vybošt’ok, Finite element modelling of high velocity impact on plate structures. Procedia Engineering 136, 162-168 (2016)

6. Z. Pelagič, M. Nágel', M. Žmindák, P. Pastorek, Finite element simulation of wear in dynamic contact problems. Dynamika tuhých a deformovatelných těles 2013, sborník přenášek z XI. mezinárodní vědecké konference, Ústí nad Labem, 9.-11. ř́ijna 2013, Ústí nad Labem: FVTM UJEP, ISBN 978-80-7414-607-7, (2013)

7. H. Danielewski, R. Banak, A. Domagala, The Experimental Analysis of Striation Pattern Created During Laser Cutting. Transcom 2013, Žilina, Slovakia (2013) 